\title{
Different sources of reactive oxygen species contribute to low potassium-induced apoptosis in cerebellar granule cells
}

\author{
ANTONELLA BOBBA, ANNA ATLANTE, VITO A. PETRAGALLO and ERSILIA MARRA \\ Istituto di Biomembrane e Bioenergetica, Consiglio Nazionale delle Ricerche, I-70126 Bari, Italy
}

Received January 14, 2008; Accepted February 21, 2008

\begin{abstract}
An early increase in ROS production is characteristic of cerebellar granule cells undergoing apoptosis in the presence of $5 \mathrm{mM} \mathrm{KCl}$. However, the sources of this increase have not been investigated in detail. In particular whether there is a single enzymatic source or the increase in ROS production is the consequence of the involvement of different enzymes has not been studied in depth. Different enzymatic pathways may indeed contribute to the upregulation of intracellular ROS production either directly or via side-chain reactions and a number of candidate enzymes are known to be involved in the apoptotic process in various cell types. The aim of this study was to identify the cellular sources of the ROS generated by CGCs undergoing apoptosis by low $\mathrm{K}^{+}$. A panel of specific inhibitors against phospholipase, cytochromes $\mathrm{P} 450$, cyclooxygenase, lipoxygenase, xanthine oxidase, ribonucleotide reductase and NADPH oxidase were used. We provide evidence that no single source of ROS can be identified in apoptotic CGCs, but the ROS generated through the arachidonic acid (AA) pathways, mainly via lipoxygenase activities, seems to be the most prominent.
\end{abstract}

\section{Introduction}

Results obtained in our and other laboratories indicate that low potassium shift of cerebellar granule cells (CGCs) increases the intracellular content of reactive oxygen species (ROS) and induces oxidative stress (1-5). ROS in CGCs resulting from low $\mathrm{K}^{+}$treatment accumulate rapidly within 30 min after treatment and reach the maximum after 3-4 h; in addition, the intracellular oxidized state has been linked to a decrease in the activity of antioxidant enzymes (5).

A number of candidate enzymes and biochemical pathways are known to be important in generating ROS leading to apoptosis in various cell types such as phospho-

Correspondence to: Dr Antonella Bobba, Istituto di Biomembrane e Bioenergetica, Consiglio Nazionale delle Ricerche, Via Amendola 165/A, I-70126 Bari, Italy

E-mail: a.bobba@ibbe.cnr.it

Key words: cerebellar granule cells, apoptosis, reactive oxygen species, inhibitors, ROS generating enzymes lipase A2 (PLA2), cyclooxygenase (COX), lipoxygenase (LOX), cytochromes P450 (CYTP450), xanthine oxidase (XOD), ribonucleotide reductase and NADPH oxidase.

The release and metabolism of unsaturated fatty acids such as arachidonic acid (AA) by phospholipase could also play an important role in ROS generation. AA released from cell membranes can affect cell proliferation and induce apoptosis directly (6) or via activation of NADPH oxidase (7). Subsequent metabolism of AA or other fatty acids by LOX, COX and CYTP450 may generate ROS thus resulting in membrane lipid peroxidation, and apoptosis (8). LOX constitute a heterogeneous family of lipid peroxidizing enzymes which are capable of oxygenating polyunsaturated fatty acids to their corresponding hydroperoxy derivatives and are endowed with both a pro- or anti-apoptotic role depending on cell type and apoptotic stimulus. COX enzymes, which are responsible for the production of bioactive prostanoid and ROS (9), have been involved in the increase of cytoplasmic ROS production in excitotoxin-stimulated CGCs (10). CYTP450 are involved in many intracellular metabolic processes and the induction of CYTP450 activity can result in increased levels of ROS (11). Consistently, CYTP450 mediate ROS generation in rat hepatocytes and the resulting oxidative stress have been linked to apoptosis $(12,13)$.

$\mathrm{XOD}$ is found to be a key enzyme in ROS production during excitotoxicity in CGCs (14) while ribonucleotide reductase is frequently involved in regulating cancer progression and is a target for antitumour therapy (15). NADPH oxidase, a flavoprotein-dependent superoxide-producing enzyme, has been implicated in ROS generation in response to drugs (16) and growth factors (17) as well as in the apoptosis of NGFdeprived sympathetic neurons (18). Recently it has been proposed that NADPH oxidase could be a major extracellular source of superoxide anion in apoptotic CGCs $(4,19)$.

Superoxide anions can also be produced as a side product of the mitochondrial electron transport chain and indeed damaged and/or uncoupled mitochondria are one of the major source of ROS production in most cells (20). However, recent reports demonstrate both that in the first hours of CGC apoptosis no mitochondrial dysfunction occurs $(2,21)$ and that cytochrome $c$ release occurs from still coupled and intact mitochondria $(22,23)$.

Our group has long been involved in the characterization of the apoptotic pathway induced by lowering extracellular potassium in CGCs in particular by analyzing the participation of ROS and mitochondria to this process. We have observed that ROS production is an early event and always 
precedes the loss of mitochondrial transmembrane potential (24), the release of cytochrome $c$ (25) and the activation of caspases (26).

Consistently, the aim of this study was to identify the cellular sources of the early ROS generated by CGCs undergoing apoptosis by low $\mathrm{K}^{+}$. Using a set of enzyme inhibitors we provide evidence that, although no single source of ROS can be identified in apoptotic CGCs, the ROS generated through the AA pathways, mainly via LOX activities, seems to be the most prominent.

\section{Materials and methods}

Materials. Tissue culture medium and fetal calf serum were purchased from Gibco (Grand Island, NY, USA) and tissue culture dishes were from Nunc (Taastrup, Denmark). All enzymes and biochemicals were from Sigma Chemicals Co. (St. Louis, MO, USA).

Cell cultures. Primary cultures of cerebellar granule cells (CGCs) were obtained from dissociated cerebellar of 7-dayold Wistar rats as previously described (27). Cells were plated in basal medium Eagle (BME) supplemented with $10 \%$ fetal calf serum, $25 \mathrm{mM} \mathrm{KCl}, 2 \mathrm{mM}$ glutamine and $100 \mu \mathrm{g} / \mathrm{ml}$ gentamycin on dishes coated with poly L-lysine. Cells were plated at a density of $1 \times 10^{6} / \mathrm{ml}$. 1b-Arabinofuranosylcytosine $(10 \mu \mathrm{M})$ was added to the culture medium $18-22 \mathrm{~h}$ after plating to prevent proliferation of non-neuronal cells.

Induction of apoptosis. At 6-7 days in vitro (DIV), cells were washed twice and switched to serum-free BME, containing $5 \mathrm{mM} \mathrm{KCl}$ (K5) supplemented with glutamine and gentamycin. Apoptotic cells are referred to as S-K5 cells. Control cells were treated identically but maintained in serum-free BME medium supplemented with $25 \mathrm{mM} \mathrm{KCl} \mathrm{(K25)} \mathrm{and}$ then referred to as $\mathrm{S}-\mathrm{K} 25$ cells (28).

Assessment of neuronal viability. Viable CGCs were quantified by counting the number of intact nuclei after lysing the cells in detergent-containing solution (29). This method has been shown to be reproducible and accurate and to correlate well with other methods of assessing cell survival/death (30). Cell counts were performed in triplicate and are reported as means $\pm \mathrm{SD}$.

Superoxide anion detection in CGCs. Superoxide anion $\left(\mathrm{O}_{2}^{-}\right)$ was detected, as previously described (5), using the $\mathrm{Fe}^{3+}$-cyt $c$ method (31). The newly formed $\mathrm{O}_{2}^{-\cdot}$ gave an increase in absorbance at $550 \mathrm{~nm}\left(\varepsilon_{550 \mathrm{~nm}}=37 \mathrm{mM}^{-1} \mathrm{~cm}^{-1}\right)$ measured using a Perkin-Elmer Lambda-5 spectrophotometer equipped with a thermostated holder (Perkin-Elmer, Foster City, CA, USA). A calibration curve was made by using an $\mathrm{O}_{2}^{-\cdot}$ producing system, i.e. xanthine plus xanthine oxidase, and an $\mathrm{O}_{2}{ }^{-}$. detection system, namely $\mathrm{Fe}^{3+}$-cyt $c$, that, in the presence of $\mathrm{O}_{2}^{-}$, gave $\mathrm{Fe}^{3+}-$ cyt $c$ with $1: 1$ stoichiometry.

ROS staining with DCFH2-DA. At 7 DIV CGCs were switched to serum-free medium containing 25 or $5 \mathrm{mM} \mathrm{KCl}$. After $3.5 \mathrm{~h}$ cells were incubated for an additional $30 \mathrm{~min}$

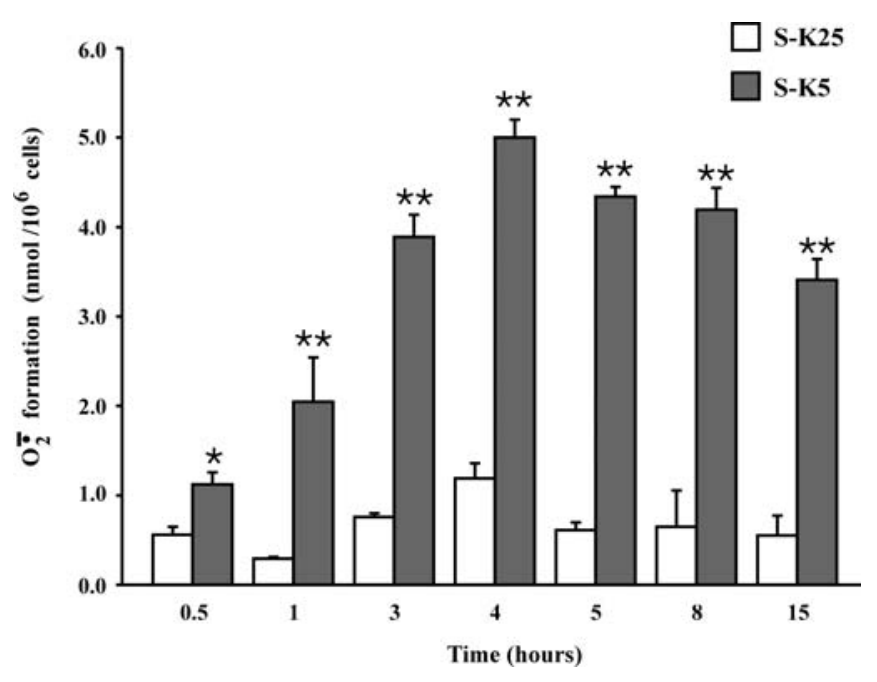

Figure 1. Superoxide anion levels in CGCs en route to apoptosis. CGCs were incubated either in high $\mathrm{KCl}(\mathrm{S}-\mathrm{K} 25)$ or in low $\mathrm{KCl}(\mathrm{S}-\mathrm{K} 5)$ serum-free culture medium and treated with $\mathrm{Fe}^{3+}$-cyt $c(10 \mu \mathrm{M})$. At different times after apoptosis induction, the culture solution was taken and the increase in absorbance at $550 \mathrm{~nm}$, due to $\mathrm{Fe}^{3+}$-cyt $c$, reduction was determined. The experimental data are reported as nmol $( \pm \mathrm{SD})$ of $\mathrm{O}_{2}{ }^{-}$formed per $10^{6}$ cells, calculated on the basis of the stoichiometry of the reaction using the extinction coefficient determined under our experimental conditions (see details in Materials and methods). The experiment was repeated 4 times with different cell preparations. Statistically significant differences are indicated by asterisks $\left({ }^{*} \mathrm{p}<0.05\right.$ and $^{* *} \mathrm{p}<0.01$ with respect to $\mathrm{S}-\mathrm{K} 25$ cells taken at the corresponding times).

with the ROS sensitive dye 2',7'-dichlorohydrofluorescein diacetate (DCFH2-DA) in order to detect cellular ROS formation. This non-fluorescent dye is deacetylated in the cytoplasm by esterases and converted into a fluorescent compound by oxidation. Thereafter, i.e. $4 \mathrm{~h}$ after induction of apoptosis, cells were then washed in PBS and fluorescence was examined and photographed under a Nikon DIAPHOT TS-100 epifluorescence microscope with excitation/emission at $495 / 515 \mathrm{~nm}$. Images were digitized with x40 epifluorescence objective and a Nikon Digital Video Camera E995 (Coolpix 995) and analyzed with the Nikon Image Analysis System (Nikon, Tokyo, Japan). In all cases, cells were exposed only for $30 \mathrm{sec}$ to UV light.

Statistical analysis. Data are expressed as means \pm SD, and statistical significance of the results was determined by one-way ANOVA using the Bonferroni post-hoc test, with statistical significance set at $\mathrm{p}<0.05$.

\section{Results}

When CGCs are switched from high (25 mM) to low (5 mM) potassium containing medium apoptosis is induced which is characterized by an early production of ROS. The time course of superoxide anion production shows a net and sustained increase of $\mathrm{O}_{2}^{-}$. peaking at $4 \mathrm{~h}$ in apoptotic (S-K5) cells with about a 5-fold increase over control cells (S-K25) (Fig. 1).

To analyze the source of ROS, we have used different inhibitors which block potential intracellular ROS-producing systems. First of all we investigated the effect of different 

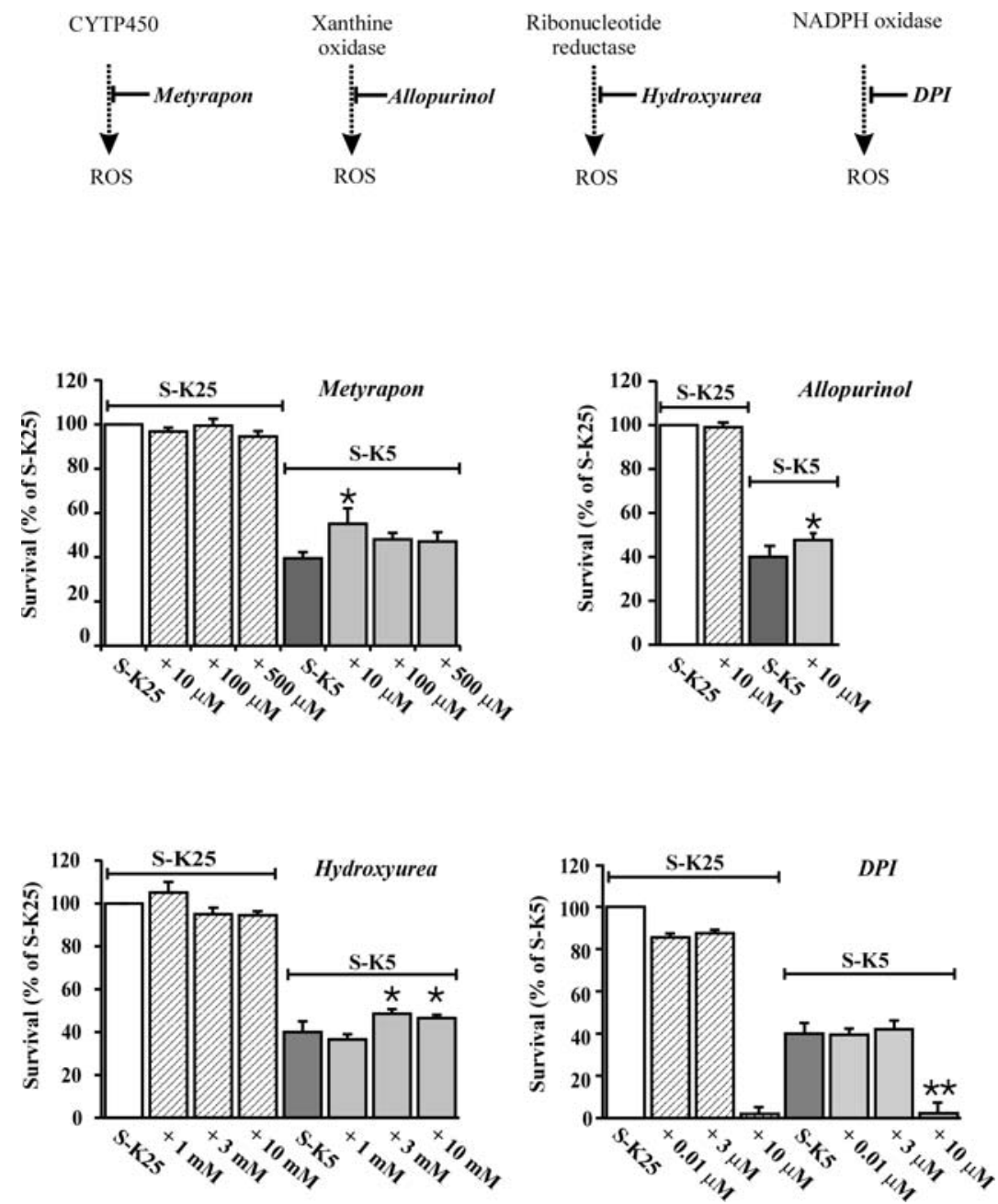

Figure 2. Effect of inhibitors of ROS-generating enzymes on cell death. Control (S-K25) and apoptotic (S-K5 cells) were treated with the different inhibitors shown in the upper part of the figure. Different concentrations of each inhibitors were used. Cell viability was determined after $24 \mathrm{~h}$ by counting the intact nuclei. Values represent the mean $( \pm \mathrm{SD})$ of three independent measurements. Statistically significant differences are indicated by asterisks $\left({ }^{*} \mathrm{p}<0.05\right.$ and ${ }^{* *} \mathrm{p}<0.01$ with respect to $\mathrm{S}-\mathrm{K} 5$ cells).

amounts of each inhibitor on the survival of both control and apoptotic cells. The inhibitors were added separately to cells and survival was measured $24 \mathrm{~h}$ after drug administration as compared to that of control cells treated with vehicle only. In Fig. 2 the effect of Metyrapon, Allopurinol, Hydroxyurea and Diphenyl iodonium (DPI), which inhibit respectively CYTP450, XOD, ribonucleotide reductase and NADPH oxidase on cell survival was investigated. Allopurinol was used at the concentration of $10 \mu \mathrm{M}$ which in previous studies (25) was found to be the appropriate concentration to inhibit XOD in this type of cell. None of these inhibitors, except DPI, was found to be toxic to S-K25 control cells. With apoptotic $\mathrm{S}-\mathrm{K} 5$ cells, it was found that $10 \mu \mathrm{M}$ Metyrapon $(55 \pm 7 \%)$ and

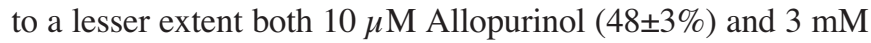
Hydroxyurea $(49 \pm 2 \%)$ slightly improved cell survival as compared with untreated S-K5 cells $(40 \pm 3 \%)(\mathrm{p}<0.05)$.

On the other hand DPI used at a concentration of $10 \mu \mathrm{M}$, which was effective in preventing ROS production during hepatocyte apoptosis (32), was found to be toxic to control (S-K25) and apoptotic (S-K5) cells with $100 \%$ death induction in both cases. This compound was still found to be partially toxic even when tested at low concentrations which have been found to be effective in preventing ROS production in sympathetic neurons (18). Indeed 0.01 and $3 \mu \mathrm{M}$ DPI still induce about $20 \%$ death in control cells while no effect on the survival of apoptotic cells was detected.

The second group of inhibitors tested was related to the arachidonic pathway of ROS generation and consisted of AACOCF3 (inhibitor of PLA2), Esculetin (general inhibitor of LOX) and Indomethacin (inhibitor of COX). Survival of control (S-K25) and apoptotic (S-K5) cells was differently influenced by these inhibitors (Fig. 3). While the effect on control cells was minimal, $5 \mu \mathrm{M}$ AACOCF3 improved survival of apoptotic cells up to $62 \pm 5 \%$ as compared to untreated apoptotic cells $(40 \pm 3 \%)(\mathrm{p}<0.01)$. Esculetin, the broad range inhibitor of lipoxygenases, induced a slight increase in cell survival of about $13 \%$ with respect to S-K5 cell alone at the three concentrations tested $(\mathrm{p}<0.05)$. Finally, Indomethacin at $0.1 \mathrm{mM}$ proved to be able to slightly improve survival with a value of about $49 \pm 3 \%$ with respect to S-K5 alone $(\mathrm{p}<0.05)$.

The availability of inhibitors against the three isoforms of lipoxygenase prompted us to investigate the effect of Baicalein (inhibitor of 12-LOX), PD146176 (inhibitor of 

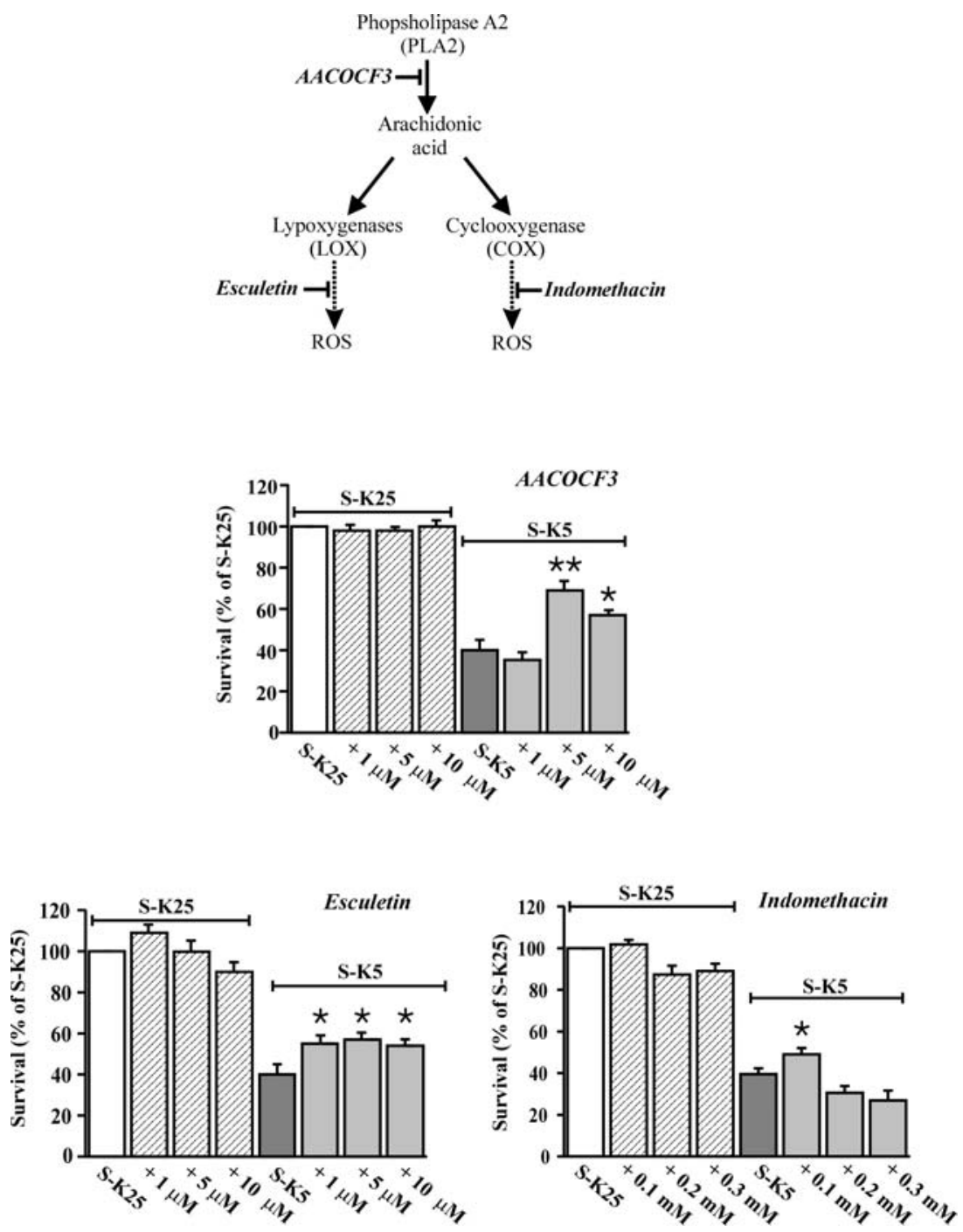

Figure 3. Effect of inhibitors of the AA pathway on cell death. Control (S-K25) and apoptotic (S-K5 cells) were treated with the inhibitors of the AA pathway (AACOCF3, Esculetin and Indomethacin). Different concentrations of each inhibitors were used. Cell viability was determined after $24 \mathrm{~h}$ by counting the intact nuclei. Values represent the mean $( \pm \mathrm{SD})$ of three independent measurements. Statistically significant differences are indicated by asterisks $(* \mathrm{p}<0.05$ and ${ }^{* *} \mathrm{p}<0.01$ with respect to S-K5 cells).

15-LOX) and MK886 (inhibitor of 5-LOX) (Fig. 4). Interestingly, $1 \mu \mathrm{M}$ Baicalein and $0.3 \mu \mathrm{M}$ PD1146176 strongly improved survival of apoptotic cells with values of $74 \pm 3 \%$ and $68 \pm 2 \%$, respectively as compared to untreated apoptotic cells $(40 \pm 3 \%)(\mathrm{p}<0.01)$. On the other hand MK886 did not show any significant effect on survival of either control or apoptotic cells at least up to $1 \mu \mathrm{M}$ but became toxic at higher concentration also on control cells.

Given that the enzymes investigated in this study are involved either directly or through side-chain reactions in ROS production, and since their inhibition was found to influence to a greater or lesser extent the survival of apoptotic CGCs, we investigated whether the improvement in cell survival found with some inhibitors correlated with a decrease in the cellular oxidation state. To do this, $\mathrm{O}_{2}{ }^{-}$ production was measured in S-K25 and S-K5 cells treated or not with the inhibitors after $4 \mathrm{~h}$ of apoptosis, a time at which the bulk of superoxide production has been shown to take place. Only one concentration of each inhibitor was used, i.e. the concentration that in the survival experiments was found to significantly inhibit the death of S-K5 cells and to be not toxic to control cells.

When CGCs were shifted to a low potassium medium

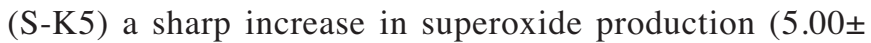
$0.17 \mathrm{nmol} \mathrm{O}_{2}^{-} / 1 \times 10^{6}$ cells) was detected after $4 \mathrm{~h}$ of apoptosis (Fig. 5) this effect being decreased by SOD used as a positive control $(\mathrm{p}<0.01)$. Apoptotic cells incubated with $10 \mu \mathrm{M}$ Allopurinol, $10 \mu \mathrm{M}$ Metyrapon and $3 \mathrm{mM}$ Hydroxyurea showed a slight decrease in $\mathrm{O}_{2}{ }^{-}$production with values of $3.53 \pm 0.14,4.05 \pm 0.18$ and $4.25 \pm 0.15 \mathrm{nmol} / 1 \times 10^{6}$ cells, respectively ( $<<0.05$ as compared to untreated S-K5 cells). A strong reduction in the formation of superoxide anion was accomplished by the inhibitors of the arachidonic acid pathway of ROS production: $5 \mu \mathrm{M}$ AACOCF3 (PLA2) and $5 \mu \mathrm{M}$ Esculetin (LOX) efficiently reduce $\mathrm{O}_{2}^{-}$production by about $50 \%$ with respect to untreated S-K5 cells $(\mathrm{p}<0.01)$. Similar results were obtained with the inhibitors of two lipoxygenase isoforms: $1 \mu \mathrm{M}$ Baicalein (12-LOX) and $0.3 \mu \mathrm{M}$ PD146176 

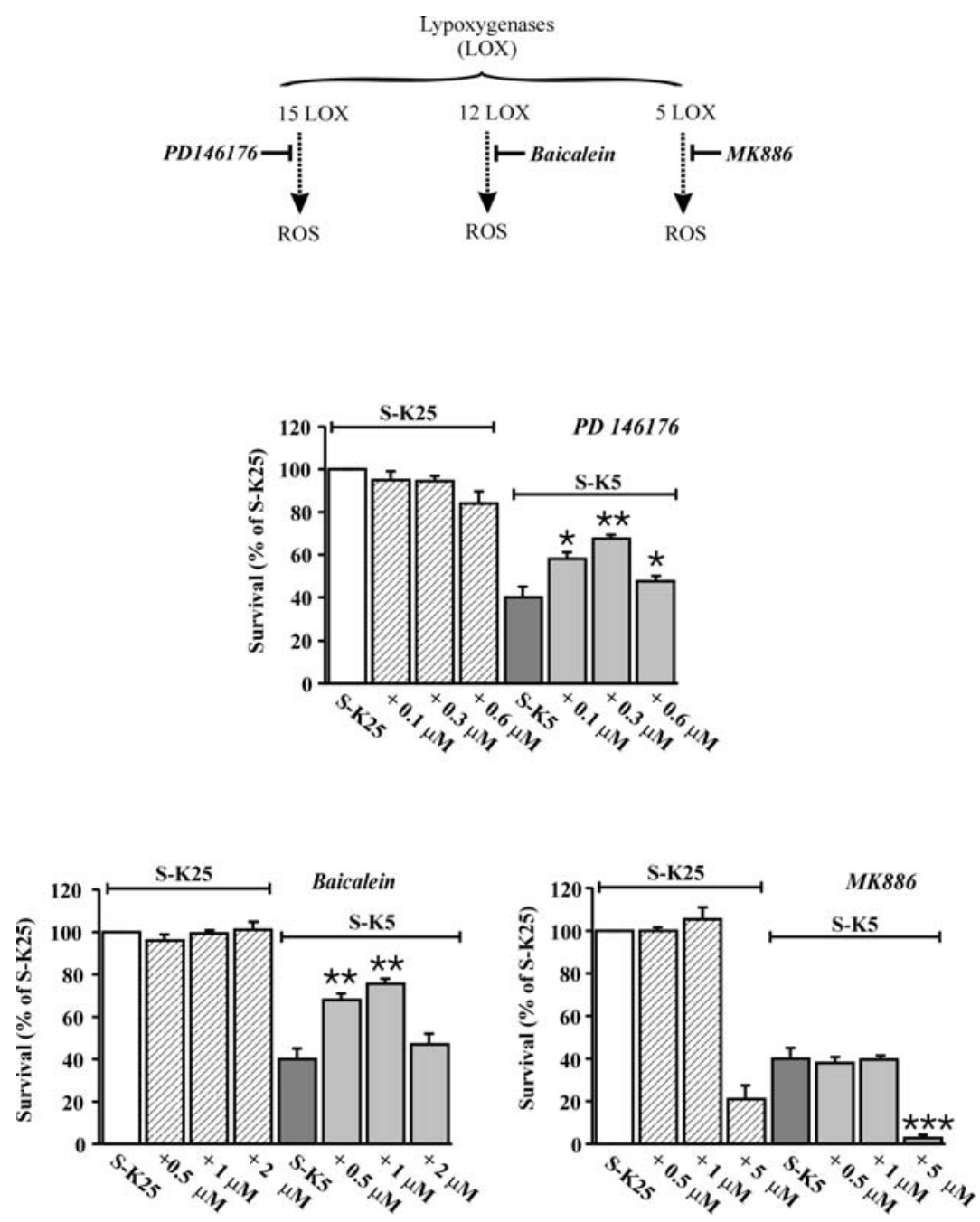

Figure 4. Effect of lipoxygenase inhibitors on cell death. Control (S-K25) and apoptotic (S-K5 cells) were treated with the inhibitors of the three lipoxygenase isoforms shown in the upper part of the figure (PD146176, Baicalein and MK886). Different concentrations of each inhibitor were used. Cell viability was determined after $24 \mathrm{~h}$ by counting the intact nuclei. Values represent the mean $( \pm \mathrm{SD})$ of three independent measurements. Statistically significant differences are indicated by asterisks $\left({ }^{*} \mathrm{p}<0.05,{ }^{* *} \mathrm{p}<0.01\right.$ and ${ }^{* * * *} \mathrm{p}<0.001$ with respect to $\mathrm{S}-\mathrm{K} 5$ cells $)$.

$(15-\mathrm{LOX})(\mathrm{p}<0.01)$. On the other hand inhibition of 5-LOX by MK886 and COX by Indomethacin decreased $\mathrm{O}_{2}^{--}$less efficiently $\left(4.03 \pm 0.08 \mathrm{nmol} / 1 \times 10^{6}\right.$ and $4.38 \pm 0.09$, respectively) $(\mathrm{p}<0.05)$. Surprisingly, in DPI-treated S-K5 cells a further increase in $\mathrm{O}_{2}^{-} \cdot$ production was detected $(5.88 \pm 0.08 \mathrm{nmol} /$ $1 \times 10^{6}$ cells).

Confirmatory results were obtained from microphotographs of sister culture samples after addition of DCFH2-DA. DCFH2-DA is a general fluorescent probe for ROS often used to detect the production of oxidizing species in cells via oxidation to its fluorescent product (DCF). Images of DCF fluorescence in S-K5 cells in the presence or absence of the inhibitors as analyzed by epifluorescence microscope are shown in Fig. 6. These qualitative results mirror and confirm what was found with the quantitative $\mathrm{O}_{2}^{-\cdot}$ production assay.

\section{Discussion}

Many studies have indicated that ROS play an important role in the progression of apoptosis induced in CGCs by lowering extracellular potassium (1-5), but the sources of ROS generation were unclear. Recently Samhan-Arias et al (19) proposed that NADPH oxidase could be a major source of extracellular superoxide anion in apoptotic CGCs. Moreover, it has also been proposed that in excitotoxin-stimulated CGCs the increase in the cytoplasmic ROS production may occur mainly via cyclooxygenase (10).

Our data show that ROS may be produced by different sources during the apoptosis of CGCs and among the enzyme systems frequently implicated in ROS generation, PLA2, 12-LOX and 15-LOX are the most prominent in ROS generation and apoptosis of CGCs in response to $\mathrm{K}^{+}$-shift.

Increasing evidence supports a signalling link between ROS and PLA2-mediated AA metabolism (33) which is often dependent on both the apoptotic stimulus and the cell type: while PLA2 is required in apoptosis induced by tumour necrosis factor $\alpha$ it is not required in Fas-induced apoptosis (34). Interestingly it has been reported that the secretory form of PLA2 rescues CGCs from apoptosis after potassium deprivation (35).

The potential involvement of PLA2 in apoptosis of CGCs was investigated using AACOCF3, an inhibitor of all PLA2 


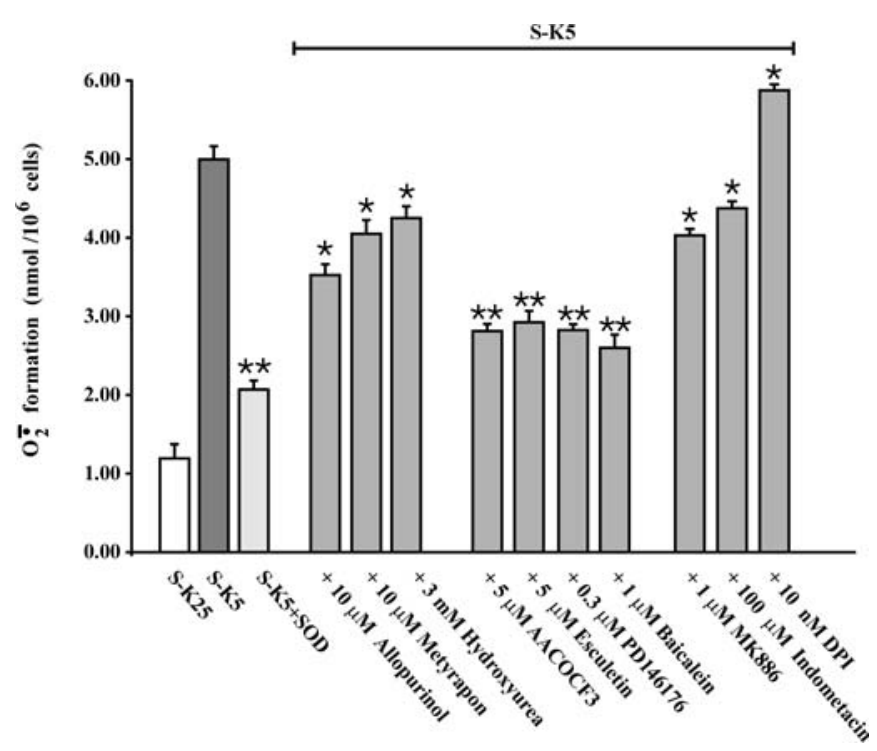

Figure 5. Effect of inhibitors of ROS-generating enzymes on the superoxide anion levels in CGCs en route to apoptosis. CGCs were incubated either in high $\mathrm{KCl}(\mathrm{S}-\mathrm{K} 25)$ or in low $\mathrm{KCl}$ (S-K5) serum-free culture medium and treated with $\mathrm{Fe}^{3+}$-cyt $c(10 \mu \mathrm{M})$ in the absence or presence of the different inhibitors. After $4 \mathrm{~h}$ of apoptosis, the culture solution was taken and the increase in absorbance at $550 \mathrm{~nm}$, due to $\mathrm{Fe}^{3+}$-cyt $c$, reduction was determined. The experimental data are reported as nmol $( \pm \mathrm{SD})$ of $\mathrm{O}_{2}^{--}$formed per $10^{6}$ cells, calculated on the basis of the stoichiometry of the reaction using the extinction coefficient determined under our experimental conditions (see details in Materials and methods). The experiment was repeated 4 times with different cell preparations. Statistically significant differences are indicated by asterisks $\left({ }^{*} \mathrm{p}<0.05\right.$ and ${ }^{* *} \mathrm{p}<0.01$ with respect to $\mathrm{S}-\mathrm{K} 5$ cells). isoforms (36). The treatment of apoptotic S-K5 cells with AACOCF3 improved cell viability as compared to $\mathrm{S}-\mathrm{K} 5$ cells alone and strongly reduced the increase in superoxide production that follows apoptosis induction. The PLA2 reaction is the primary pathway through which arachidonic acid is released from phospholipids and most biological effects of AA are attributable to its metabolism by three different groups of enzymes: LOX, COX and CYTP450.

Although we do not know the details of the downstream mediators of PLA2 in the low potassium signalling pathway leading to generation of ROS, our findings using inhibitors indicate that subsequent AA metabolism by 12 and 15-LOX is involved. The pan LOX inhibitor, Esculetin which blocks activity by binding to LOX (37) did not induce apoptosis on its own but was effective in preventing cell death. A similar improvement was also exerted by Baicalein, a specific inhibitor of 12-LOX (38) and by PD146176 a highly specific inhibitor of 15-LOX (39). Conversely, MK886, an inhibitor of 5-LOX (40) did not improve survival. Moreover, the pan LOX inhibitor (Esculetin), the 12-LOX inhibitor (Baicalein) and the 15-LOX inhibitor (PD146176) drastically reduced ROS production in S-K5 cells thus suggesting that ROS might be derived from activation of these two isoforms in apoptotic signalling in response to $\mathrm{K}^{+}$-shift.

These results are consistent with recent findings showing that 12 -LOX is the primary LOX expressed in the brain (41) and that the AA metabolic pathway mediated by 12-LOX activation is an important source of ROS in neurons where oxidative stress is induced by different stimuli (42-44). More-

\section{S-K5}

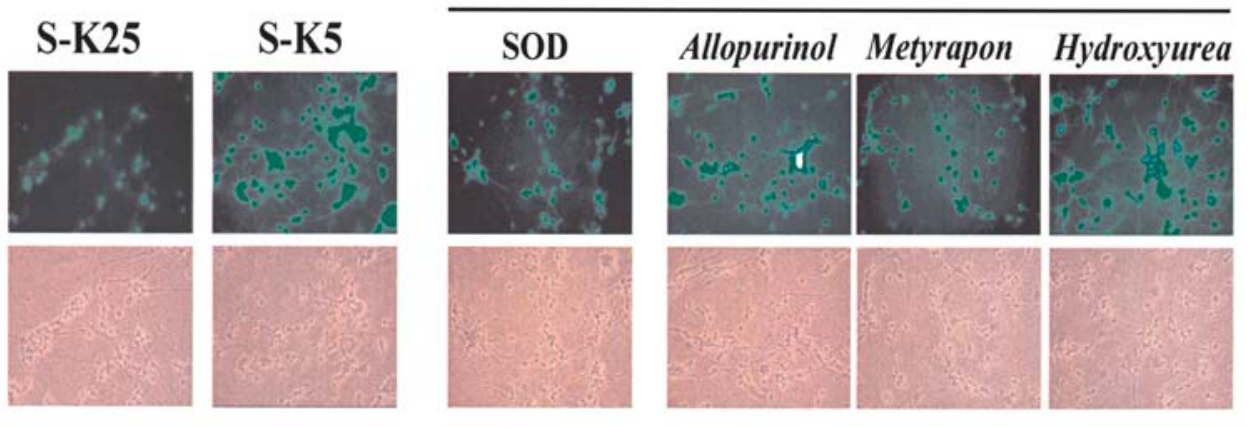

S-K5

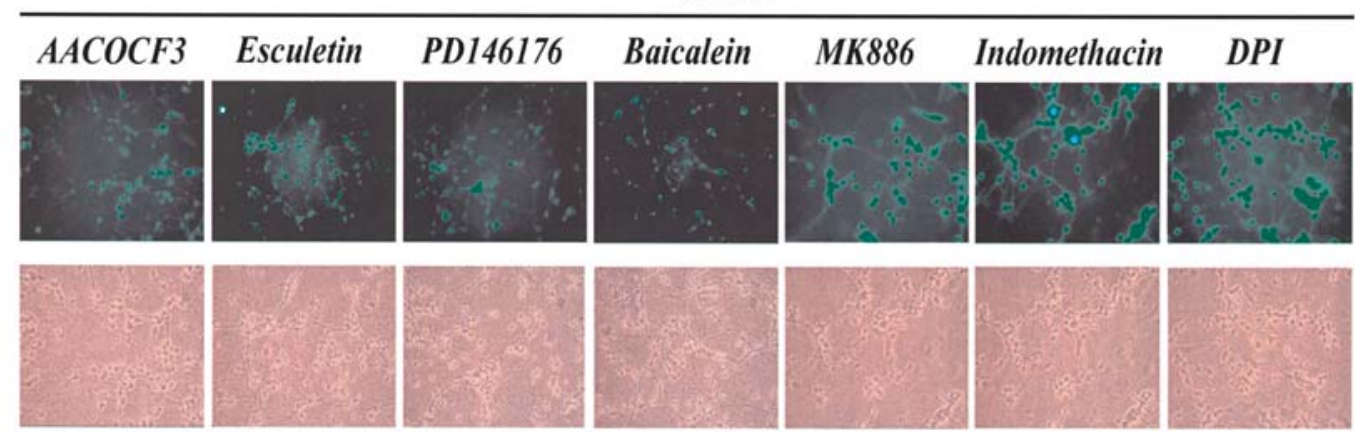

Figure 6. Fluorescence micrographs of CGCs loaded with DCFH2-DA. Apoptosis was induced in CGCs for $4 \mathrm{~h}$ either in the presence or absence of different inhibitors. DCFH2-DA $(10 \mu \mathrm{M})$ was added to the culture medium for $30 \mathrm{~min}$ and samples were treated as detailed in Materials and methods. For each inhibitor, both fluorescence and the correspondent phase contrast micrograph were taken in a NIKON DIAPHOT TS-100 epifluorescence microscope (equipped with a 40x objective and 495/515 nm excitation/emission filters). Images were digitized by using a Nikon Digital Video Camera E995 (Coolpix 995). When indicated the inhibitors were added at the time of apoptosis induction. 
over, the different LOX isoforms seem to be specifically involved in neurodegenerative process as blockade of 12-LOX but not of 5-LOX expression prevents $B$ amyloid-induced apoptosis (45). On the other hand while 5-LOX is found to be expressed in the central nervous system and is crucial for neurogenesis (46) its involvement in the apoptotic route is rather confusing since 5-LOX inhibitors has been claimed either to induce (47) or to prevent apoptosis (48).

AA can act as the substrate for two other enzymes besides LOX, namely COX and CYTP450 but their involvement in low potassium-induced apoptosis in CGCs seems to be of minor importance because inhibitors of these enzymes do not have a significant protective effect. Indeed, notwithstanding that CYTP450 represent a substantial source of ROS and AA-derivative metabolites (49), the inhibitor Metyrapone (50) can only partially prevent cell death (15\% improvement) and superoxide production (19\% decrement) with respect to untreated apoptotic cells. This result suggest that CYTP450 are at least partially involved in the apoptosis progression of CGCs.

Indomethacin (51) was used as an inhibitor to investigate the role of COX. It is known that this enzyme, in particular the type 2 isoform, is involved both in the mechanism of neurodegeneration and in mediating synaptic plasticity $(52,53)$. However, it had only a minor effect on both cell survival and ROS production.

Ribonucleotide reductase is a radical enzyme involved in de novo deoxyribonucleotide synthesis and therefore plays a central role in the formation and control of the optimal dNTP levels inside cells. It is variously reported that ribonucleotide reductase inhibitors may have anticarcinogenic effects and induce apoptosis (15) or may be endowed with the possibility to inhibit the induction of apoptosis via oxidative stress (54). This enzyme seems to be only marginally involved in the apoptosis of CGCs since its inhibition by hydroxyurea (55) has only a small effect both in improving cell survival and reducing superoxide anion levels.

Similar results were obtained when the involvement of XOD was investigated by using its specific inhibitor Allopurinol. It has been reported that ROS produced by XOD can induce apoptosis in rat lung after pulmonary reexpansion (56) or in $\mathrm{MPP}^{+}$(1-methyl-4-phenylpyridinium)treated CGCs (57). Moreover, XOD was shown to be the main ROS producing-enzyme during excitotoxicity in CGCs (14) and in the reoxygenation injury of ischemic cerebral endothelial cells (58). Conversely, its involvement in the apoptosis of CGCs induced by low potassium was shown in the present study to be minimal since its inhibition by Allopurinol only partially affected cell survival and superoxide production.

The involvement of NADPH oxidase deserves a specific discussion. Different studies have implicated the plasma membrane NADPH oxidase as one of the major ROS generatingenzymes in neuronal cells $(4,18-19)$. Surprisingly, our results showed that DPI does not have any protective effect on apoptotic CGCs. Micromolar concentrations of DPI were toxic to both control and apoptotic cells. On the other hand, whilst nanomolar concentrations of DPI did not block apoptosis nor improve survival, surprisingly, $10 \mathrm{nM}$ DPI led to an increase in superoxide production of up to $5.88 \mathrm{nmol}$
$\mathrm{O}_{2}^{-} \cdot / 1 \times 10^{6}$ cells as compared to the value of $5.00 \pm 0.17 \mathrm{nmol}$ $\mathrm{O}_{2}^{-} / 1 \times 10^{6}$ cells $(\mathrm{p}<0.05)$ found in S-K5 apoptotic cells.

As far the participation of mitochondria in ROS production is concerned it should be stressed that the experimental approach used in this study cannot be used to investigate the production of ROS by mitochondria. Indeed we have already demonstrated that the different inhibitors of the mitochondrial respiratory chain are toxic towards S-K25 control cells (59) and can induce by themselves an overproduction of ROS at the mitochondrial level. Furthermore increased production of ROS by mitochondria takes place when these organelles are damaged and/or uncoupled and we have previously demonstrated that in apoptotic CGCs cytochrome $c$ release, caused by ROS, occurs from mitochondria that are still coupled (23). These results are in full agreement with a recent report by Jekabsons et al (21) who showed that the early increase in intracellular superoxide, which occurs in low potassium apoptosis of CGCs, is not due to a failure in mitochondrial respiration since no dysfunction of this organelle was detectable during the first $5 \mathrm{~h}$ of apoptosis, consistent with the report by Atlante et al (2). Similarly, Cai et al (22) reported that mitochondrial generation of ROS occurs only after cytochrome $c$ release. Taken together these findings suggest that ROS production by mitochondria in the first $4 \mathrm{~h}$ of apoptosis in CGCs is not a major event.

In summary, our results using a panel of inhibitors towards different enzymes that produce ROS suggest that the increase in ROS production, which takes place early during the apoptosis of CGCs, cannot be ascribed to a single enzymatic source. Nevertheless, ROS generation through the AA pathways, mainly via 15 -LOX and 12 -LOX, seems to be most prominent with only minor contributions from $\mathrm{COX}$, CYTP450, ribonucleotide reductase and XOD. Unfortunately, the involvement and contribution of NADPH oxidase to the oxidative stress in apoptotic CGCs could not be ascertained by the approach used in this study because of the toxic effect of DPI. On the other hand, the neuroprotective effects of PLA2 and LOX inhibitors may relate to down-regulation of free radical formation under our cell culture conditions. Further studies using different and more direct approaches, such as enzymatic activity assays and protein expression profiles, will be directed to dissecting the contribution of PLA2 and LOX in regulating the progression of apoptosis in CGCs.

\section{Acknowledgements}

The authors wish to thank Professor Shawn Doonan for his critical reading of the manuscript. This study was partially financed by FIRB RBNE01ZK8F_003 to A.A.; CNR-MIUR Fondo FISR 16/10/2000 to A.A.; and MIUR Contributi straordinari di ricerca/aree obiettivo 1 to E.M.

\section{References}

1. Schulz JB, Weller $M$ and Klockgether T: Potassium deprivation-induced apoptosis of cerebellar granule neurons: a sequential requirement for new $\mathrm{mRNA}$ and protein synthesis, ICE-like protease activity, and reactive oxygen species. J Neurosci 16: 4696-4706, 1996. 
2. Atlante A, Gagliardi S, Marra E and Calissano P: Neuronal apoptosis in rats is accompanied by rapid impairment of cellular respiration and is prevented by scavengers of reactive oxygen species. Neurosci Lett 245: 127-300, 1998.

3. Valencia A and Moran J: Role of oxidative stress in the apoptotic cell death of cultured cerebellar granule neurons. J Neurosci Res 64: 284-297, 2001.

4. Martin-Romero FJ, Garcia-Martin E and Gutierrez-Merino C: Inhibition of oxidative stress produced by plasma membrane NADH oxidase delays low-potassium-induced apoptosis of cerebellar granule cells. J Neurochem 82: 705-715, 2002.

5. Atlante A, Bobba A, Calissano P, Passarella S and Marra E: The apoptosis/necrosis transition in cerebellar granule cells depends on the mutual relationship of the antioxidant and the proteolytic systems which regulate ROS production and cytochrome $c$ release en rout to death. J Neurochem 84: 960-971, 2003.

6. Surette ME, Fonteh AN, Bernatchez $\mathrm{C}$ and Chilton FH: Pertubations in the control of cellular arachidonic acid levels block cell growth and induce apoptosis of HL60 cells. Carcinogenesis 5: 757-763, 1999.

7. Brash AR: Arachidonic acid as a bioactive molecule. J Clin Invest 107: 1339-1345, 2001.

8. Maccarrone M, Melino G and Finazzi Agrò A: Lipoxygenases and their involvement in programmed cell death. Cell Death Diff 8: 776-784, 2001.

9. Strauss KI and Marini AM: Cyclooxygenase-2 inhibition protects cultured cerebellar granule neurons from glutamatemediated cell death. J Neurotrauma 19: 627-638, 2002.

10. Boldyrev AA, Carpenter DO, Huentelman MJ, Peters CM and Johnson P: Sources of reactive oxygen species production in excitotoxin-stimulated cerebellar granule cells. Biochem Biophys Res Commun 256: 320-324, 1999.

11. Cross AR and Jones OT: Enzymatic mechanisms of superoxide production. Biochim Biophys Acta 1057: 281-298, 1991.

12. Shiba D and Shimamoto N: Attenuation of endogenous oxidative stress-induced cell death by cytochrome P450 inhibitors in primary cultures of rat hepatocytes. Free Radic Biol Med 27: 1019-1026, 1999

13. Ferrara R, Zanovello A, Bortolato S, White IN and Manno M: Bioactivation and cytotoxicity of 1,1-dichloro-2,2,2-trifluorethane (HCFC-123) in isolated rat hepatocytes. Pharmacol Toxicol 88: 192-197, 2001.

14. Atlante A, Calissano P, Bobba A, Giannattasio S, Marra E and Passarella S: Glutamate neurotoxicity, oxidative stress and mitochondria (Review). FEBS Lett 497: 1-5, 2001.

15. Rosenberger G, Fuhrmann G, Grusch M, et al: The ribonucleotide reductase inhibitor trimidox induces c-myc and apoptosis of human ovarian carcinoma cells. Life Sci 67: 3131-3142, 2000.

16. Lee YS, Kang YS, Lee SH and Kim JA: Role of NAD(P)H oxidase in the tamoxifen-induced generation of reactive oxygen species and apoptosis in HepG2 human hepatoblastoma cells. Cell Death Differ 7: 925-932, 2000.

17. Suzukawa K, Miura K, Mitsushita J, Resau J, Hirose K, Crystal R and Kamata T: Nerve growth factor-induced neuronal differentaition requires Rac1-regulated reactive oxygen species. J Biol Chem 275: 13175-13178, 2000.

18. Tammariello SP, Quinn MT and Estus S: NADPH oxidase contributes directly to oxidative stress and apoptosis in nerve growth factor-deprived sympathetic neurons. J Neurosci 20: RC53, 2000.

19. Samhan-Arias AK, Martin-Romero FJ and Gutierrez-Merino C: Kaempferol blocks oxidative stress in cerebellar granule cells and reveals a key role for reactive oxygen species production at the plasma membrane in the commitment to apoptosis. Free Radic Biol Med 37: 48-61, 2004.

20. Lenaz G: The mitochondrial production of reactive oxygen species: mechanisms and implications in human pathology (Review). IUBMB Life 52: 159-164, 2001

21. Jekabsons MB and Nicholls DG: Bioenergetic analysis of cerebellar granule neurons undergoing apoptosis by potassium/ serum deprivation. Cell Death Differ 13: 1595-1610, 2006.

22. Cai J and Jones DP: Superoxide in apoptosis. Mitochondrial generation triggered by cytochrome c loss. J Biol Chem 273: 11401-11404, 1998.

23. Bobba A, Canu N, Atlante A, Petragallo V, Calissano P and Marra E: Proteasome inhibitors prevent cytochrome c release during apoptosis but not in excitotoxic death of cerebellar granule neurons. FEBS Lett 515: 8-12, 2002.
24. Atlante A, De Bari L, Bobba A, Marra E, Calissano P and Passarella S: Cytochrome $c$, released form cerebellar granule cells undergoing apoptosis or excitotoxic death, can generate protonmotive force and drive ATP synthesis in isolated mitochondria. J Neurochem 86: 591-604, 2003.

25. Atlante A, Calissano P, Bobba A, Azzariti A, Marra E and Passarella S: Cytochrome $c$ is released from mitochondria in a reactive oxygen species (ROS)-dependent fashion and can operate as a ROS scavenger and as a respiratory substrate in cerebellar neurons undergoing excitotoxic death. J Biol Chem 275: 37159-37166, 2000.

26. Bobba A, Atlante A, Giannattasio S, Sgaramella G, Calissano P and Marra E: Early release and subsequent caspase-mediated degradation of cytochrome $\mathrm{c}$ in apoptotic cerebellar granule cells. FEBS Lett 457: 126-130, 1999.

27. Levi G, Aloisi F, Ciotti MT and Gallo V: Autoradiographic localization and depolarization-induced release of acidic amino acids in differentiating cerebellar granule cell cultures. Brain Res 290: 77-86, 1984.

28. D'Mello SR, Galli C, Ciotti T and Calissano P: Induction of apoptosis in cerebellar granule neurons by low potassium: inhibition of death by insulin-like growth factor I and cAMP. Proc Natl Acad Sci USA 90: 10989-10993, 1993.

29. Volontè C, Ciotti T and Battistini L: Development of a method for measuring cell number: application to CNS primary neuronal cultures. Cytometry 17: 274-276, 1994.

30. Stefanis L, Park DS, Friedman WJ and Greene LA: Caspasedependent and -independent death of camptothecin-treated embryonic cortical neurons. J Neurosci 19: 6235-6247, 1999.

31. Forman HJ and Fridovich I: Superoxide dismutase: a comparison of rate constants. Arch Biochem Biophys 158: 396-400, 1973.

32. Herrera B, Murillo MM, Alvarez-Barrientos A, Beltran J, Fernandez $M$ and Fabregat I: Source of early reactive oxygen species in the apoptosis induced by transforming growth factorbeta in fetal rat hepatocytes. Free Radic Biol Med 36: 16-26, 2004.

33. Woo C-H, Lee ZW, Kim BC, Ha KS and Kim JH: Involvement of cytosolic phospholipase A2, and the subsequent release of arachidonic acid, in signalling by Rac for the generation of intracellular reactive oxygen species in Rat-2 fibroblasts. Biochem J 348: 525-530, 2000.

34. Taketo MM and Sonoshita M: Phospolipase A2 and apoptosis (Review). Biochim Biophys Acta 1585: 72-76, 2002.

35. Arioka M, Cheon SH, Ikeno Y, Nakashima S and Kitamoto K: A novel neurotrophic role of secretory phospholipases A2 for cerebellar granule neurons. FEBS Lett 579: 2693-2701, 2005.

36. Cummings BS, Mchowat J and Schnellmann RG: Phospholipase A2s in cell injury and death. J Pharmacol Exp Ther 294: 793-799, 2000.

37. Moore SA, Giordano MJ, Kim HY, Salem N Jr and Spector AA: Brain microvessel 12-hydroxyeicosatetraenoic acid is the (S) enantiomer and is lipoxygenase derived. J Neurochem 57: 922-999, 1991.

38. Huang HC, Wang HR and Hsieh LM: Antiproliferative effect of baicalein, a flavonoid from a Chinese herb, on vascular smooth muscle cell. Eur J Pharmacol 251: 91-93, 1994.

39. Sendobry SM, Cornicelli JA, Welch K, et al: Attenuation of diet-induced atherosclerosis in rabbits with a highly selective 15-lipoxygenase inhibitor lacking significant antioxidant properties. Br J Pharmacol 120: 1199-1206, 1997.

40. Ford-Hutchinson AW, Gresser M and Young RN: 5-Lipoxygenase (Review). Annu Rev Biochem 63: 383-417, 1994.

41. Phillis JW, Horrocks LA and Farooqui AA: Cyclooxygenases, lipoxygenases, and epoxygenases in CNS: their role and involvement in neurological disorders (Review). Brain Res Rev 52: 201-243, 2006.

42. Stanciu M, Wang Y, Kentor R, et al: Persistent activation of ERK contributes to glutamate-induced oxidative toxicity in a neuronal cell line and primary cortical neuron cultures. J Biol Chem 275: 12200-12206, 2000.

43. Li Y, Maher P and Schubert D: A role for 12-lipoxygenase in nerve cell death caused by glutathione depletion. Neuron 19: 453-463, 1997.

44. Khanna S, Roy S, Ryu H, Bahadduri P, Swaan PW, Ratan RR and Sen CK: Molecular basis of vitamin E action: tocotrienol modulates 12-lipoxygenase, a key mediator of glutamateinduced neurodegeneration. J Biol Chem 278: 43508-43515, 2003. 
45. Lebeau A, Terro F, Rostene W and Pelaprat D: Blockade of 12lipoxygenase expression protects cortical neurons from apoptosis induced by beta-amyloid peptide. Cell Death Differ 11: 875-884, 2004.

46. Manev H, Uz T, Manev R and Zhang Z: Neurogenesis and neuroprotection in the adult brain. A putative role for 5-lipoxygenase? Ann NY Acad Sci 939: 45-51, 2001.

47. Ghosh J and Myers CE: Inhibition of arachidonate 5-lipoxygenase triggers massive apoptosis in human prostate cancer cells. Proc Natl Acad Sci USA 95: 13182-13187, 1998.

48. Maccarrone M, Salucci ML, Melino G, Rosato N and FinazziAgro A: The early phase of apoptosis in human neuroblastoma CHP100 cells is characterized by lipoxygenase-dependent ultraweak light emission. Biochem Biophys Res Commun 265: 758-762, 1999.

49. Zangar RC, Davydov DR and Verma S: Mechanisms that regulate production of reactive oxygen species by cytochrome P450 (Review). Toxicol Appl Pharmacol 199: 316-331, 2004.

50. Brezna B, Kweon O, Stingley RL, et al: Molecular characterization of cytochrome P450 genes in the polycyclic aromatic hydrocarbon degrading Mycobacterium vanbaalenii PYR-1 Appl Microbiol Biotechnol 71: 522-532, 2006.

51. Chen YC, Lin-Shiau SY and Lin JK: Involvement of reactive oxygen species and caspase 3 activation in arsenite-induced apoptosis. J Cell Physiol 177: 324-333, 1998.

52. Qin W, Peng Y, Ksiezak-Reding H, et al: Inhibition of cyclooxygenase as potential novel therapeutic strategy in N141I presenilin-2 familial Alzheimer's disease. Mol Psychiatry 11: 172-181, 2006.
53. Hewett SJ, Uliasz TF, Vidwans AS and Hewett JA: Cyclooxygenase- 2 contributes to $\mathrm{N}$-methyl-D-aspartate-mediated neuronal cell death in primary cortical cell culture. J Pharmacol Exp Ther 293: 417-425, 2000.

54. Kanno S, Kakuta M, Kitajima Y, et al: Preventive effect of trimidox on oxidative stress in U937 cell line. Biol Pharm Bull 30: 994-998, 2007.

55. O'Donnell VB, Spycher S and Azzi A: Involvement of oxidants and oxidant-generating enzyme(s) in tumour-necrosis-factoralpha-mediated apoptosis: role for lipoxygenase pathway but not mitochondrial respiratory chain. Biochem J 310: 133-141, 1995.

56. Saito S, Ogawa J and Minamiya Y: Pulmonary reexpansion causes xanthine oxidase-induced apoptosis in rat lung. Am J Physiol Lung Cell Mol Physiol 289: L400-L406, 2005.

57. González-Polo RA, Rodríguez-Martín A, Morán JM, Niso M, Soler G and Fuentes JM: Paraquat-induced apoptotic cell death in cerebellar granule cells. Brain Res 1011: 170-176, 2004.

58. Beetsch JW, Park TS, Dugan LL, Shah AR and Gidday JM: Xanthine oxidase-derived superoxide causes reoxygenation injury of ischemic cerebral endothelial cells. Brain Res 786: 89-95, 1998.

59. Bobba A, Atlante A, Azzariti A, Sgaramella G, Calissano P and Marra E: Mitochondrial impairment induces excitotoxic death in cerebellar granule cells. Int J Mol Med 13: 873-876, 2004. 